\title{
Molecular evidence for transplacental transmission of Theileria equi from carrier mares to their apparently healthy foals
}

\author{
M.T.E.P. Allsopp ${ }^{\mathrm{a}, \mathrm{b}, 1}$, B.D. Lewis ${ }^{\mathrm{b}}$ and B.L. Penzhorn ${ }^{\mathrm{b}}$ \\ ${ }^{a}$ Onderstepoort Veterinary Institute, Private Bag X5, Onderstepoort 0110, South Africa \\ ${ }^{b}$ Department of Veterinary Tropical Diseases, Faculty of Veterinary Science, University \\ of Pretoria, Private Bag X4, Onderstepoort 0110, South Africa
}

\section{Abstract}

The intra-erythrocytic parasite Theileria equi is one of two tick-transmitted causative agents of equine piroplasmosis. Piroplasms of T. equi can be transmitted across the equine placenta and once a horse is infected, it appears to remain a lifelong carrier, since anti-theilerial drugs suppress but do not eliminate the parasite. Carrier mares may transmit the organism to their offspring and this may result in abortion or neonatal piroplasmosis, but observations by some researchers suggest that foals may be born as carriers yet remain apparently healthy. Using a T. equi-specific oligonucleotide probe, we have determined that transplacental transmission occurs early in equine foetal development and that carrier mares may give birth to healthy carrier foals. Investigation of parasite levels and the effect of maternal colostrum on the newborn suggests that colostral T. equi antibody may act to suppress parasitaemia in the newborn, reducing the incidence of clinical neonatal piroplasmosis.

\section{Article Outline}

1. Introduction

2. Materials and methods

2.1. Equine samples

2.2. DNA extraction, PCR amplification and probing 
3. Results

4. Discussion

5. Conclusion

Acknowledgements

References

\section{Introduction}

The first description of an equine disease referred to as 'biliary fever' was made by Hutcheon (1895) the colonial veterinary surgeon of the Cape Colony, South Africa. Later, Theiler (1901) observed intra-erythrocytic parasites in blood samples, which he attributed to equine malaria but which were recognised by Laveran (1901) as intraerythrocytic piroplasms. Subsequently, the cause of equine piroplasmosis was found to be two distinct parasites (Nuttall and Strickland, 1912), Piroplasma caballi (Babesia caballi) and Piroplasma equi (now Theileria equi, Mehlhorn and Schein, 1998). Both parasites are transmitted to equids by ticks of the genera Hyalomma and Rhipicephalus, but whereas $T$. equi can undergo transplacental transmission in the mammalian host, there is no reliable evidence that $B$. caballi can pass from mare to foal in this way. Equine piroplasmosis is thought to be indigenous to Asia (Friedhoff, 1982) but as a result of centuries of movement of horses for personal transport, as draft animals, and for the lucrative thoroughbred racing industry, both parasites have become distributed worldwide and active transmission is possible wherever competent vectors occur. Many countries outside southern Africa forbid the importation of horses because of the high prevalence of asymptomatic carrier animals in the region, among which are reservoir populations of zebra (Zweygarth et al., 2002). The South African thoroughbred racing industry is particularly badly affected by equine piroplasmosis, acute infections resulting in missed training sessions and races and hence serious loss of income to owners and trainers. Income is also lost to owners through abortion in stud mares which are T. equi carriers. The cost of B. caballi infection to the racing industry in South Africa is less severe than that of $T$. equi because infection in carrier animals can be sterilised by suitable drug treatment, whereas T. equi infection may be suppressed by chemotherapy but not 
eliminated (De Waal and Van Heerden, 2004). T. equi infection in carrier mares is cited as the most common cause of equine abortion (De Waal, 1992). Aborted foetuses show lesions characteristic of equine piroplasmosis and it is assumed that once the parasite crosses the placenta and infects the foetus, the result is either an abortion or a foal born with neonatal babesiosis. There are no records of investigations into how or when transplacental transmission takes place and in this study we aim to increase the understanding of such transmission by determining the stage of gestation at which foetuses become infected, the mechanism by which such infection may occur and whether abortion or neonatal piroplasmosis are inevitable outcomes. We also investigate the effect of natural colostral antibody on the progress of congenital T. equi infection in new-born foals.

\section{Materials and methods}

\subsection{Equine samples}

Blood samples ( $5 \mathrm{ml}$ aliquots in EDTA) were collected from pregnant mares serologically positive for T. equi which were held at the Department of Theriogenology, University of Pretoria Faculty of Veterinary Science, Onderstepoort, South Africa. A sample was also collected from an animal which was serologically negative for both $B$. caballi and T. equi as a control for subsequent molecular probing investigations (Table 1).

\section{Table 1.}

DNA probe and serological verification of the carrier status of the mares involved in the study

\begin{tabular}{|l|l|l|}
\hline Sample & T. equi probe & IFAT \\
\hline V127 & + & + \\
\hline V82 & + & + \\
\hline V90 & + & + \\
\hline V39 & + & + \\
\hline
\end{tabular}




\begin{tabular}{|l|l|l|}
\hline Sample & T. equi probe & IFAT \\
\hline V22 & - & + \\
\hline V26 & + & + \\
\hline V81 & + & + \\
\hline V132 & + & + \\
\hline V27 & - & + \\
\hline V69 & + & + \\
\hline V131 & + & + \\
\hline L49 & + & + \\
\hline V12 & + & + \\
\hline V15 & - & + \\
\hline V20 & - & + \\
\hline U14 & + & + \\
\hline V71 & + & + \\
\hline Neg. horse & - & + \\
\hline,+ positive result;,- negative result. \\
\hline
\end{tabular}

To investigate the stage of pregnancy at which equine foetuses become infected with $T$. equi, prostaglandin-induced abortions ([Volkman and De Kramer, 1991] and [Volkmann et al., 1995]) were performed on six of the mares, one at 4 months gestation, three at 5 months and two at 7 months gestation. Blood samples were collected from each mare immediately before prostaglandin administration for indirect fluorescence antibody test (IFAT, Lewis, 1998) and DNA extraction. Cord blood was collected from each foetus before these underwent euthanasia by intra-cardial injection of phenobarbitone sodium (Euthanaze, Centaur). Foetal spleens were dissected out and held frozen at $-20{ }^{\circ} \mathrm{C}$ prior to DNA extraction. No microscopic examination of foetal blood smears was undertaken. In order to determine the infection status of animals after parturition, whole blood for DNA probing, and serum samples for IFAT were collected from six T. equi carrier mares 
V27, V81, V15, L49, U14 and V132 and their apparently healthy new-born foals within $12 \mathrm{~h}$ post partum to avoid any contact with ticks.

To investigate whether natural equine colostrum containing T. equi antibodies would have any effect on congenital infections in new-born foals, DNA probe and IFAT examination of the foals of three known carrier mares, foal V12, foal V20 and foal V132 were followed up for 2-3 weeks after birth. Because it is difficult to predict the exact time a mare will foal down, after assessment of the mares to confirm their readiness to foal, the animals were transferred from the paddocks, after treatment to remove ticks, to the tick-free quarantine section of the Onderstepoort Veterinary Academic Research Unit (OVARU), Faculty of Veterinary Science, University of Pretoria. Parturitions were induced and blood samples ( $5 \mathrm{ml}$ aliquots) for DNA extraction and for serology were collected from the foals before ingestion of colostrum. Thereafter, blood and serum samples were collected daily from the foals and blood smears were examined for the presence of T. equi parasites. Samples from foal V12, one of three born in the isolation facility, were processed before the birth of the other two foals (foal V20 and foal V132). As the results of both $T$. equi probing and IFAT for foal V12 were consistent during the 21 days of observation, it was decided that a sampling period of 14 days would be sufficient for the other two foals, to minimise stress on both foals and dams.

\subsection{DNA extraction, PCR amplification and probing}

Foetal spleens were macerated with $1 \mathrm{ml}$ sterile phosphate-buffered saline solution. DNA was extracted from whole blood ( $1 \mathrm{ml}$ aliquots) or spleen extracts ( $1 \mathrm{~g}$ aliquots $)$ as follows: one part (v/v) of a slurry consisting of 20\% (w/v) Chelex 100 (Bio-Rad, Hercules, CA, USA), 1\% (v/v) Tween 20, 1\% (v/v) Nonidet P-40 and 1\% SLS (Stein and Raoult, 1992) was added to four parts (v/v or w/v) of the sample under test. The mixture was heated to $90^{\circ} \mathrm{C}$ for $10 \mathrm{~min}$ and centrifuged for $10 \mathrm{~min}$ at $12,000 \times \mathrm{g}$. Supernatants were removed and total nucleic acid content [NA] was determined by spectrophotometry. Nucleic acid concentrations of each sample were adjusted to $250 \mathrm{ng} / \mu \mathrm{l}$ with nuclease-free water and samples were stored at $-20^{\circ} \mathrm{C}$ prior to PCR and probing.

Amplifications were carried out in $50 \mu \mathrm{l}$ volumes using primers 989 and 990 (Allsopp et al., 1993) which target the V4 loop of piroplasm small subunit ribosomal RNA (srRNA) 
genes, at an annealing temperature of $56^{\circ} \mathrm{C}$. Reaction mixtures contained PCR buffer, $2.5 \mathrm{mM} \mathrm{MgCl}_{2}, 0.2 \mathrm{mM}$ each dNTP, $0.2 \mu \mathrm{M}$ each primer, $2 \mathrm{U}$ Expand Taq polymerase (Roche Diagnostics, Switzerland) and $3 \mu 1$ prepared DNA. All reactions included a negative (horse) and a positive (T. equi $18 \mathrm{~S}$ plasmid) control. Reaction conditions on a GeneAmp PCR System 9700 (Perkin-Elmer Applied Biosystems) were: initial denaturation, 2 min at $95{ }^{\circ} \mathrm{C}, 35$ cycles of $30 \mathrm{~s}$ at $95{ }^{\circ} \mathrm{C}, 30 \mathrm{~s}$ at $56^{\circ} \mathrm{C}$ and $45 \mathrm{~s}$ at $72{ }^{\circ} \mathrm{C}$; final extension, $5 \mathrm{~min}$ at $72{ }^{\circ} \mathrm{C}$; hold at $4{ }^{\circ} \mathrm{C}$.

Aliquots (10 $\mu$ l) of each amplicon were slot blotted as described (Saiki et al., 1986) on to nylon membranes (Hybond $\mathrm{N}+$, Amersham International). Membranes were prehybrised for at least $1 \mathrm{~h}$ at $50{ }^{\circ} \mathrm{C}$ in sodium dodecyl sulphate (SDS)/sodium phosphate buffer, $\mathrm{pH}$ 7.5 (Church and Gilbert, 1984). A T. equi-specific oligonucleotide probe BE1, 5'-GAC AAA CGC CAA GCG CAG-3' (Fig. 1, Allsopp, 1994), was 3'-end labelled as described (Anon., 1991) and added directly to the hybridisation bottle. Membranes were hybridised at $50{ }^{\circ} \mathrm{C}$ for a minimum of $1 \mathrm{~h}$. Blots were washed as described (Allsopp, 1994), followed by stringency washing at $60^{\circ} \mathrm{C}$ for $1 \mathrm{~min}$, before being sealed in polythene and autoradiographed at $-70{ }^{\circ} \mathrm{C}$ for $24 \mathrm{~h}$. No probing for B. caballi was undertaken because of the lack of specificity of the probe (Fig. 1)

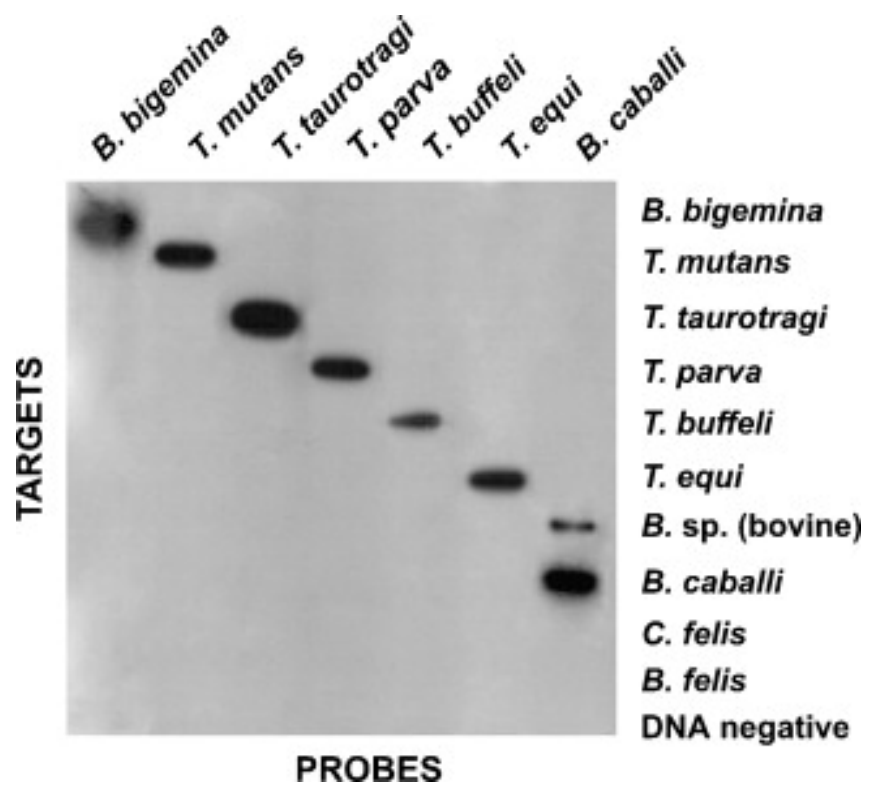


Fig. 1. Autoradiograph showing the specificity of oligonuceotide probes for amplified $18 \mathrm{~S}$ gene targets of varoius Theileria and Babesia species. The T. equi probe is specific for the T. equi target. The B. caballi probe cross-reacts with Babesia sp. (bovine) target.

\section{Results}

Table 1 shows the T. equi carrier status of the mares included in the study determined by both IFAT and T. equi-specific probing of PCR amplified DNA. Although all mares were serologically positive for the parasite, mares V22, V27, V15 and V20 were T. equi probe negative. Both IFAT and PCR/probing results were negative for the control horse. The specificity of the oligonucleotide probe for T. equi is shown in Fig. 1.

Results of the experiment to investigate the stage of pregnancy at which equine foetuses become infected with T. equi are shown in Table 2. At the time abortions were performed, all mares were seropositive and probe-positive for T. equi. Cord blood from all aborted foetuses was serologically negative but DNA extracted from the macerated spleens of the foetuses was probe-positive. The stage of gestation at which foetuses were aborted ranged from 4 months to 7 months.

Table 2.

Mares and aborted foetuses: post-abortion serology and DNA probing results for T. equi

\begin{tabular}{|l|l|l|l|l|l|}
\hline Animal & Sample & Foetal age & IFAT & DNA probe \\
\hline V26 & Mare & & + & + \\
\hline & Foetus & 7 months & - & + \\
\hline \multicolumn{7}{|c|}{} \\
\hline V90 & Mare & & + & + \\
\hline & Foetus & 7 months & - & + \\
\hline V127 & Mare & & & \\
\hline & Foetus & 5 months & - & + \\
\hline
\end{tabular}




\begin{tabular}{|c|c|c|c|c|}
\hline Animal & Sample & Foetal age & IFAT & DNA probe \\
\hline \multirow[t]{2}{*}{ L49 } & Mare & & + & + \\
\hline & Foetus & 5 months & - & + \\
\hline \multirow[t]{2}{*}{ U14 } & Mare & & + & + \\
\hline & Foetus & 5 months & - & + \\
\hline \multirow[t]{2}{*}{ V82 } & Mare & & + & + \\
\hline & Foetus & 4 months & - & + \\
\hline Negative horse & & & - & - \\
\hline
\end{tabular}

+ , positive result; -, negative result.

Serological and DNA probing results for T. equi obtained from six mares and their apparently healthy newborn foals are shown in Table 3 . All mares were both serologically and probe-positive for T. equi and all foals were probe-positive. All but two of the foals (foal L49 and foal U14) were T. equi serologically positive.

Table 3.

Serology and DNA probing results for carrier mares and their apparently healthy newborn foals

\begin{tabular}{|l|l|l|l|l|}
\hline Animal & Sample & IFAT & DNA probe \\
\hline V27 & Mare & + & + \\
\hline & Foal & + & + \\
\hline \multicolumn{5}{|l|}{} \\
\hline V81 & Mare & + & + \\
\hline & Foal & + & + \\
\hline
\end{tabular}




\begin{tabular}{|c|c|c|c|}
\hline Animal & Sample & IFAT & DNA probe \\
\hline \multirow[t]{2}{*}{ V15 } & Mare & + & + \\
\hline & Foal & + & + \\
\hline \multirow[t]{2}{*}{ L49 } & Mare & + & + \\
\hline & Foal & - & + \\
\hline \multirow[t]{2}{*}{ U14 } & Mare & + & + \\
\hline & Foal & - & + \\
\hline \multirow[t]{2}{*}{ V132 } & Mare & + & + \\
\hline & Foal & + & + \\
\hline Negative horse & & - & - \\
\hline
\end{tabular}

+ , positive result; -, negative result.

Table 4 shows the probing and serology results obtained from the three foals (foal V12, foal V20 and foal V132) which were isolated from field infection and followed up to investigate the effect of natural equine colostrum on congenital T. equi infection. All precolostral samples from the foals were serologically negative for T. equi and all foals subsequently showed positive IFAT titres (minimum 1/80) during the observation period. Two of the animals (foal V12 and foal V20) were probe-positive on pre-colostral DNA, and foal V12 DNA samples were consistently probe-positive, except for one doubtful result, during the 3 weeks of observation. A blood smear taken from foal V132 on day 14 of sampling after birth clearly showed a small number of parasitised erythrocytes. 
Table 4.

DNA probe and IFAT analysis from new-born foals fed natural colostral antibody

\begin{tabular}{|c|c|c|c|c|c|c|}
\hline Day & $\begin{array}{l}\text { V12 foal } \\
\text { probe }\end{array}$ & $\begin{array}{l}\text { V12 foal } \\
\text { IFAT }\end{array}$ & $\begin{array}{l}\text { V20 foal } \\
\text { probe }\end{array}$ & $\begin{array}{l}\text { V20 foal } \\
\text { IFAT }\end{array}$ & $\begin{array}{l}\text { V132 foal } \\
\text { probe }\end{array}$ & $\begin{array}{l}\text { V132 foal } \\
\text { IFAT }\end{array}$ \\
\hline $\begin{array}{l}\text { Pre- } \\
\text { colostrum }\end{array}$ & + & - & + & - & - & - \\
\hline 1 & + & $1 / 640$ & + & $1 / 640$ & + & $1 / 640$ \\
\hline 2 & $?$ & $1 / 640$ & - & $1 / 320$ & + & $1 / 320$ \\
\hline 3 & + & $1 / 640$ & + & $1 / 640$ & + & $1 / 1280$ \\
\hline 4 & + & $1 / 640$ & + & $1 / 320$ & + & $1 / 640$ \\
\hline 5 & + & $1 / 640$ & + & $1 / 1280$ & + & $1 / 160$ \\
\hline 6 & + & $1 / 640$ & + & $1 / 640$ & + & $1 / 160$ \\
\hline 7 & + & $1 / 640$ & - & $1 / 320$ & + & $1 / 320$ \\
\hline 8 & + & $1 / 640$ & + & $1 / 1280$ & + & $1 / 80$ \\
\hline 9 & + & $1 / 640$ & - & $1 / 160$ & - & $1 / 160$ \\
\hline 10 & + & $1 / 640$ & - & $1 / 320$ & + & $1 / 640$ \\
\hline 11 & + & $1 / 640$ & - & $1 / 320$ & + & $1 / 320$ \\
\hline 12 & + & $1 / 320$ & + & $1 / 320$ & - & $1 / 320$ \\
\hline 13 & + & $1 / 320$ & + & nd & - & $1 / 320$ \\
\hline 14 & + & $1 / 320$ & + & nd & + & $1 / 640$ \\
\hline 15 & + & $1 / 160$ & nd & nd & nd & nd \\
\hline 16 & + & $1 / 320$ & nd & nd & nd & nd \\
\hline 17 & + & $1 / 320$ & nd & nd & nd & nd \\
\hline 18 & + & $1 / 320$ & nd & nd & nd & nd \\
\hline 19 & + & $1 / 160$ & nd & nd & nd & nd \\
\hline 20 & + & $1 / 640$ & nd & nd & nd & nd \\
\hline 21 & + & $1 / 320$ & nd & nd & nd & nd \\
\hline
\end{tabular}

+ , positive; -, negative; ?, unclear result; nd, not done. 


\section{Discussion}

It has long been suspected, on the basis of positive serological results, that foals may be born as carriers of T. equi and yet may be healthy (Marcelo Labruna, personal communication). A short communication published in the Veterinary Record in 2004 describes T. equi infection in two offspring born in the UK to a carrier mare which had been imported from Portugal, where T. equi is endemic. Both animals, aged 2 and 5 years old, were complement fixation test (CFT) and IFAT positive and both showed T. equi parasites in peripheral blood smears, but were otherwise healthy. The authors conclude that the most likely route of transmission is transplacental (Phipps and Otter, 2004). It has been suggested that transplacental transmission results from abnormal placentation ([Du Plessis and Basson, 1966] and [Erbsloh, 1975]). The authors suggest that either placental damage may allow maternal and foetal blood to mix, or that reverse erythroblastosis foetalis may occur, allowing parasites to cross the placenta. Both suggestions are plausible explanations for the occurrence of such transmission in naturally aborted foetuses but it is unlikely that all six of the therapeutically aborted foetuses examined in the present study (Table 2) would have abnormal placentation. Furthermore, the results of the probe analysis carried out on six naturally born foals (Table 3) suggest that parasite transmission occurs in pregnancies where placentation is normal. Transfer of parasites during natural placental breakdown occurring as a result of normal birth cannot be ruled out but investigation of this possibility is beyond the scope of this study.

It is possible that the mechanism by which parasite transmission occurs in normal pregnancies may be specific to equine gestational physiology. Horses have what is known as semiplacenta diffusa incompleta (Gerneke, 1985). During development, the equine embryo switches from embryonic nutrition (utilising the contents of the yolk sac) to histotrophic nutrition during the formation of the chorion while the micro-cotyledons are formed. Normal haemotrophic nutrition is established once the placenta is fully formed. During the histotrophic stage, which commences at about day 40 of gestation and continues to about day 150 , the embryo is nourished by histotroph, a mixture of uterine gland secretions, desquamated epithelial cells and maternal red blood cells. The maternal erythrocytes are believed to provide a source of iron for the foetus but this study suggests 
that they may also provide a direct pathway for the passage of T. equi parasites across the developing placenta to infect the foetus. It is possible that $B$. caballi parasites may also be transferred by this mechanism, but clinical cases of B. caballi are rare in South Africa, and as parasitaemia in B. caballi infections is low (De Waal and Van Heerden, 2004), it is unlikely that parasites would be observed in blood smears from neonates. The lack of specificity of the $B$. caballi probe precluded its use as a diagnostic tool in this study. The earliest abortion carried out during the study was at approximately 130 days gestation and the foetus was probe-positive for T. equi. Foetuses aborted at approximately 150 and 210 days also yielded T. equi probe-positive spleens. These results are consistent with the hypothesis presented in the previous paragraph, and they suggest that transplacental transfer of parasites occurs very early in foetal development. Since equine foetuses do not begin to develop antibody-producing cells until at least day 240 of gestation, the negative serological results obtained from the foetal blood are to be expected.

The positive T. equi probing results obtained from the six new-born foals (Table 3) indicate that they were born as carriers of the parasite, but all were certified as healthy by qualified veterinarians and they showed no clinical signs of piroplasmosis. It is highly unlikely that natural tick transmission could have occurred in the field to account for these results since the blood samples were collected within $12 \mathrm{~h}$ of birth. Four of the six foals were also IFAT-positive for T. equi antibodies, indicating that they had ingested colostrum from their dams before the blood sample collection. Samples from the two foals which were IFAT-negative had been collected prior to colostrum ingestion. The negative IFAT results for the pre-colostral foals (foal V12, foal V20, foal V132) presented in Table 4 indicate that the foetus does not produce anti-T. equi antibodies in utero, despite the presence of the parasite in its blood. As maternal antibodies do not cross the equine epitheliochorial placenta (Tizard, 1996), the foals' blood became positive for anti-T. equi antibodies only after ingestion of colostrum. The consistent IFAT positive results for all three foals during the sampling period, coupled with the fluctuating probe-positive results, suggest that the colostral antibodies failed to eliminate the congenital T. equi infection but that they may be acting to control the level of parasitaemia, allowing the development of an endemically stable state between the 
parasite and the host. This situation has been observed in mature animals (De Waal and Van Heerden, 2004) but cannot be proved for foals from the results obtained in this study. The negative probing results (Table 4) obtained with some samples from foal V20 and foal V132 suggest that parasite numbers in the sample under test were below the limits of detection of the probe (calculated as parasitaemia of between $3 \times 10^{-8} \%$ and $3 \times 10^{-9} \%$, Allsopp, 1994). This would appear to be the situation with foal V132, where negative probing results were obtained on days 12 and 13 of sampling, but a positive probing result and positive blood smear were obtained on day 14 (Table 4).

In a study of foals to compare the presence and incidence of colostral antibody and antibody produced as a result of first natural infection, it was found that colostral antibody persisted in the foals for up to 4 months after birth. Thereafter, although the congenital infection status of the animals was unknown, the foals became serologically negative until they were infected naturally by tick-transmitted parasites (De Waal, 1995). A possible explanation of this effect can be inferred from the results obtained in this study although it was not possible to continue the study long enough for confirmation. The detection of $T$. equi in a foetus as early as 4 months of gestation indicates that transplacental transmission takes place long before the foetal immune system is sufficiently developed to recognise molecules as being foreign (Tizard, 1996) and parasites already present in the system are likely to be recognised as self by the neonate. Antigenic differences in parasites transmitted during subsequent natural infection would thus induce an immune response in congenitally infected animals. No information is available as to the time at which innate immune responses start to operate within the developing foetus, although it is likely that such mechanisms moderate parasitaemia levels in the young foal before full T-cell mediated adaptive responses are operational.

\section{Conclusion}

Although this study did not allow for statistical testing of specific time points, the consistency of the data presented here clearly indicate that transplacental transmission of T. equi parasites occurs across a normal placenta and that such transfer may occur as early as the first trimester of pregnancy. If the explanation of the mechanism of transmission is correct, it would be impossible to prevent foetuses becoming infected in 
utero and we suggest that congenital T. equi infection in the foals of carrier mares is a relatively normal occurrence. The outcome of such infection will undoubtedly be influenced by the number of parasites infecting the foetus, since in naturally occurring $T$. equi abortions and neonatal piroplasmosis cases, parasitaemias of more than $50 \%$ are frequently observed (De Waal and Van Heerden, 2004). In apparently healthy new-born carrier foals, it appears that the parasites are not recognised as foreign and we can speculate that maternal antibodies ingested with colostrum, as well as innate immune responses, may act to control levels of parasitaemia during the foals' early months of life.

\section{References}

Allsopp, 1994 Allsopp, M.T.E.P., 1994. The phylogeny of Theileria, Babesia and related parasites and the development of species-specific probes for diagnostic purposes. Ph.D. Thesis, University of the Witwatersrand, Johannesburg, South Africa. Allsopp et al., 1993 B.A. Allsopp, A.H. Baylis, M.T.E.P. Allsopp, T. Cavalier- Smith, R.P. Bishop, D.M. Carrington, B. Sohanpal and P. Spooner, Discrimination between six species of Theileria using oligonucleotide probes which detect small subunit ribosomal RNA sequences, Parasitology 107 (1993), pp. 157-165.

Anon., 1991 Anon., Promega Protocols and Applications Guide (2nd ed.), Promega Corporation, Madison, Wisconsin, USA (1991).

Church and Gilbert, 1984 G.M. Church and W. Gilbert, Genomic sequencing, Proc. Natl. Acad. Sci. U.S.A. 81 (1984), pp. 1991-1995.

De Waal, 1992 D.T. De Waal, Equine piroplasmosis: a review, Br. Vet. J. 148 (1992), pp. $6-13$.

De Waal, 1995 De Waal, D.T., 1995. Distribution, transmission and serodiagnosis of Babesia equi and Babesia caballi in South Africa. Ph.D. Thesis, University of Pretoria, Pretoria, South Africa.

De Waal and Van Heerden, 2004 D.T. De Waal and J. Van Heerden, Equine piroplasmosis. In: J.A.W. Coetzer and R.C. Tustin, Editors, Infectious Diseases of Livestock, Oxford, Southern Africa (2004), pp. 425-434. 
Du Plessis and Basson, 1966 J.L. Du Plessis and P.A. Basson, Babesiosis in aborted equine foetuses: a report on two cases in South Africa, J. South Afr. Vet. Med. Assoc. 37 (1966), pp. 267-269.

Erbsloh, 1975 J.K.E. Erbsloh, Babesiosis in the newborn foal, J. Reprod. Fertil. Suppl. 23 (1975), pp. 725-726.

Friedhoff, 1982 K.T. Friedhoff, Die Piroplasmen der equiden - Bedeutung für den Internationalen Pferdeverkehr, Berl. Münch. Tierärtzl. Wochenschr. 95 (1982), pp. 368374.

Gerneke, 1985 W.H. Gerneke, Veterinary Embryology, Department of Anatomy, Faculty of Veterinary Science, University of Pretoria, South Africa (1985).

Hutcheon, 1895 D. Hutcheon, Biliary fever, Ag. J. Cape of Good Hope 8 (1895), pp. 1718.

Laveran, 1901 A. Laveran, Contribution à l'étude du Piroplasma equi, C. R. Séances Soc. Biol. Fil. 53 (1901), pp. 385-388.

Lewis, 1998 Lewis, B.D., 1998. Transplacental transmission of Babesia equi in horses and chemotherapy of small Babesia species. PhD Thesis, University of Pretoria, Pretoria, South Africa.

Mehlhorn and Schein, 1998 H. Mehlhorn and E. Schein, Redescription of Babesia equi Laveran, 1901 as Theileria equi, Parasitol. Res. 84 (1998), pp. 467-475.

Nuttall and Strickland, 1912 G.H.F. Nuttall and C. Strickland, On the occurrence of two species of parasites in equine "piroplasmosis" or "biliary fever", Parasitology 5 (1912), pp. 65-96.

Phipps and Otter, 2004 L.P. Phipps and A. Otter, Transplacental transmission of Theileria equi in two foals born and reared in the United Kingdom, Vet. Rec. 154 (2004), pp. 406-408.

Saiki et al., 1986 R.K. Saiki, T.L. Bugawan, G.T. Horn, K.B. Mullis and H.A. Ehrlich, Analysis of enzymatically amplified $\beta$-globin and HLA-DQ $\alpha$ DNA with allele-specific oligonuceotide probes, Nature 324 (1986), pp. 163-166.

Stein and Raoult, 1992 A. Stein and D. Raoult, A simple method for the amplification of DNA from paraffin embedded tissues, Nucleic Acids Res. 20 (1992), pp. 5237-5238. 
Theiler, 1901 A. Theiler, Die Pferde-Malaria, Schweiz. Arch. Tierheilkd. 43 (1901), pp. 253-280.

Tizard, 1996 I. Tizard, Veterinary Immunology, an Introduction, W.B. Saunders Company, Philadelphia, USA (2004) 512 pp.

Volkman and De Kramer, 1991 D.H. Volkman and K.G.M. De Kramer, Prostaglandin E 2 as an adjunct to the induction of abortion in mares, J. Reprod. Fertil. Suppl. 44 (1991), pp. $722-723$.

Volkmann et al., 1995 D.H. Volkmann, H.J. Bertschinger and M.L. Schulman, The effect of prostaglandin $\mathrm{E}_{2}$ on the cervices of dioestrous and prepartum mares, Reprod. Domest. Anim. 30 (1995), pp. 240-244.

Zweygarth et al., 2002 E. Zweygarth, L.M. Lopez-Rebollar and P. Meyer, In vitro isolation of equine piroplasms derived from Cape mountain zebra (Equus zebra zebra) in South Africa, Onderstepoort J. Vet. Res. 69 (2002), pp. 197-200.

Corresponding author. Tel.: +27 12 5298253; fax: +27 125298312 .

${ }^{1}$ Present address: PO Box 13041, Onderstepoort 0110, South Africa. 